In the preoperative echocardiogram (Figure 1,Dl), a line drawn on the anterior border of the ascending aorta bisects the PA. Postoperatively (Figure 1,D2), the body of the PA has clearly moved anterior to that line, away from the $\mathrm{LM}$, whose original posterior curvature is straightened on the postoperative study. CT angiographic sections at the origin of the LM from the aorta (Figure 1, E1 [preoperative] and $E 2$ [postoperative]) and at the level of the bifurcation of the LM into the left anterior descending and left circumflex coronary arteries (Figure 1, F1 [preoperative] and F2 [postoperative]) show the same phenomenon. An increase in distance between the PA and the virtual common origin of the coronaries (preoperative $1 \mathrm{~mm}$, postoperative $5.8 \mathrm{~mm}$ ) is demonstrated (Figure 1, E2). Distally, at the bifurcation of the PA (Figure 1, G1 [preoperative] and G2 [postoperative]), most of the PA is anterior to the aorta. Comparison of preoperative CT reconstructions viewed from the patient's right and left sides (Figure $1, H I$ and $I I$, respectively) with postoperative views (Figure $1, H 2$ and $I 2$, respectively) confirms the anterior bowing of the PA that we noted at surgery, serving to increase the distance between the aorta and
PA. Through that enlarged neoaortopulmonary window, the uncompressed takeoffs of the RCA and LM are seen from both sides (Figure 1, H2 and I2). Before bifurcating, the LM (Figure 1, E2 vs E1 and $F 2$ vs $F 1$ ) takes a straight course postoperatively and has lost the posterior curvature seen preoperatively. We believe that the fulcrum of motion is not the pulmonary annulus, but rather the attachment of the infundibulum to the right ventricular mass. When the PA is foreshortened by moving the bifurcation anteriorly (and closer to that fulcrum), the main PA arches, allowing the proximal main pulmonary artery to move away from the coronaries. To our knowledge, this is the first imaging analysis to demonstrate desirable anatomic effects of PA translocation.

\section{References}

1. Brothers J, Gaynor JW, Paridon S, Lorber R, Jacobs M. Anomalous aortic origin of a coronary artery with an interarterial course: understanding current management strategies in children and young adults. Pediatr Cardiol. 2009; 30:911-21

2. Mainwaring RD, Reddy VM, Reinhartz O, Petrossian E, MacDonald M, Nasirov T, et al. Anomalous aortic origin of a coronary artery: medium-term results after surgical repair in 50 patients. Ann Thorac Surg. 2011;92:691-7.

\title{
Perventricular device closure of ventricular defects in 235 young children: A single-center experience
}

\author{
Hua-Shan Xu, MD, ${ }^{a}$ Kamran Yunus Inamdar, MM, ${ }^{\mathrm{b}}$ Khan Mohammed Firoj, MM, ${ }^{\mathrm{a}}$ and \\ Wen-Zeng Zhao, MM, ${ }^{\mathrm{a}}$ Zhengzhou, Henan, and Urumqi, Xin Jiang, China
}

Perventricular device closure of ventricular septal defect (PDCVSD) is no longer a novel modality, ${ }^{1,2}$ and current research is focused on the indications and long-term outcomes of the technique. ${ }^{3}$ We report 235 ventricular septal defect (VSD) cases with indications for PDCVSD from September 2010 to May 2013.

\section{MATERIALS AND METHODS}

PDCVSD was indicated for perimembranous, subarterial, or muscular VSD when the defects were 4 to $8 \mathrm{~mm}$ in size and $2 \mathrm{~mm}$ away from the arterial valve. Of 235 cases, 203 were perimembranous and 32 were

\footnotetext{
From the Cardiovascular Surgery Department, ${ }^{a}$ The First Affiliated Hospital of Zhengzhou University, Institute of Clinical Medical Research of Universities Henan, Zhengzhou, Henan, China; and Cardiovascular Surgery Department, ${ }^{\text {b }}$ The First Affiliated Hospital of Xinjiang Medical University, Urumqi, Xin Jiang, China.

Disclosures: Authors have nothing to disclose with regard to commercial support.

Received for publication June 18, 2013; revisions received July 31, 2013; accepted for publication Aug 9, 2013; available ahead of print Sept 26, 2013.

Address for reprints: Hua-Shan Xu, MD, Cardiovascular Surgery Department, The First Affiliated Hospital of Zhengzhou University, Zhengzhou 450052, Henan,

China (E-mail: xhsay@hotmail.com).

J Thorac Cardiovasc Surg 2013;146:1551-3

0022-5223/\$36.00

Copyright (c) 2013 by The American Association for Thoracic Surgery

http://dx.doi.org/10.1016/j.jtcvs.2013.08.004
}

subarterial; patient ages ranged from 6 months to 12 years and weights from 6 to $36 \mathrm{~kg}$. Occluder size (waist) was 2- to $4-\mathrm{mm}$ larger than the defect size, as measured using transesophageal echocardiogram. A symmetric occluder was the default choice, but an asymmetric occluder was selected when a defect was near the aortic valve. ${ }^{4}$

\section{SURGICAL PROCEDURE}

A transesophageal echocardiogram probe is placed in a supine patient after anesthesia administration. A lower midline incision $(3-4 \mathrm{~cm})$ is made and the lower sternum is sawed open. The pericardium is cut and suspended. A 4-0 prolene purse-string suture is placed in the selected puncture spot. Heparin is administered $(1 \mathrm{mg} / \mathrm{kg})$ via a central venous pressure line. A guidewire is introduced into the right ventricle and through the defect into the left ventricle, and a catheter is then introduced via the guidewire into the left ventricle to form a passage. The occluder is inserted into the defect and opened. After confirming that residual shunt and tricuspid and aortic valve regurgitations are absent, the occluder is released. The purse-string suture is knotted, and the chest is closed using a pericardial drainage tube. Protamine is not used. The surgery lasts 20 to 60 minutes. Aspirin is 


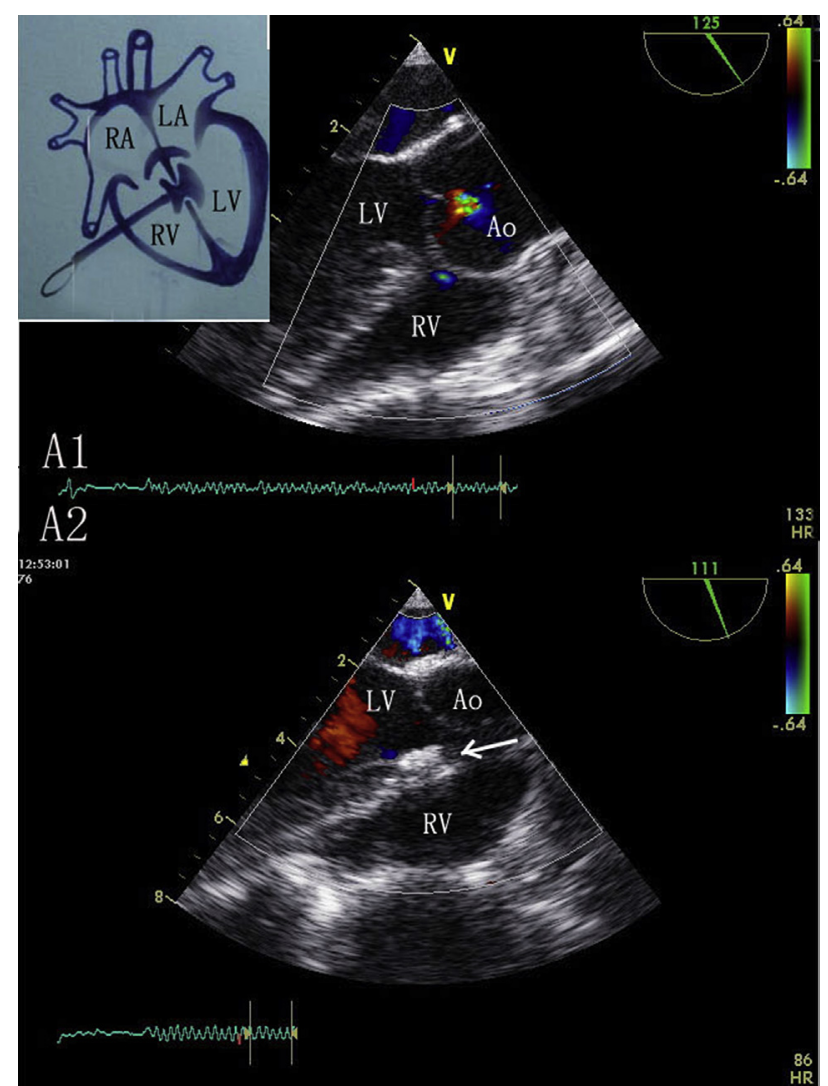

FIGURE 1. A comparison of ventricular septal defect (VSD) before and after operation with transesophageal echocardiogram surveillance. The inset depicts the procedure; white arrows show the occluder. $R A$, Right atrium; $L A$, left atrium; $R V$, right ventricle; $L V$, left ventricle; $A o$, aorta.

administered orally (1-2 $\mathrm{mg} / \mathrm{kg}$ daily) for 3 months. Follow-ups are conducted in the postoperative first, third, sixth, and 12th months using transthoracic echocardiography and electrocardiogram.

\section{RESULTS}

Of 235 patients, $223(94.90 \%)$ were successfully occluded. The other 12 cases were converted to a VSD repair (VSDR) procedure using cardiopulmonary bypass (CPB) due to irritating tachycardia (2 patients), new aortic regurgitation (5 patients), occluder migration ( 2 patients), and failure to find the defect (3 patients). One patient with late third-degree atrioventricular block underwent VSDR using CPB during his third month of follow-up; his heart rate resumed a normal rhythm on the $23 \mathrm{rd}$ day postoperatively. There was no moderate tricuspid valve regurgitation, and no death occurred (see Figure 1).

In total, 216 patients presented no atrioventricular block, residual shunts, or aortic or tricuspid valve regurgitations after 12-month follow-up. The complication data are shown in Table 1.
TABLE 1. Complications and countermeasures

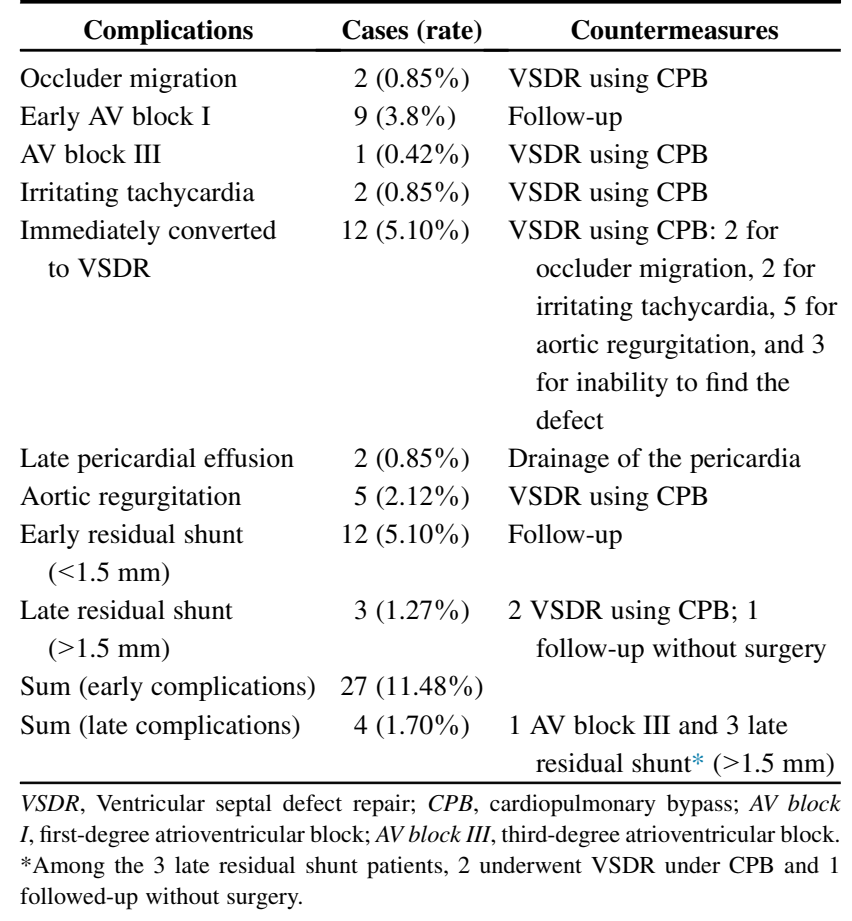

\section{DISCUSSION}

Our team designed several general principles to determine the indications for PDCVSD. First, the defect must be approximately 4 to $8 \mathrm{~mm}$ in size. A very small VSD is hard to find, and a VSD $>8 \mathrm{~mm}$ makes the occluder unstable and susceptible to migration. Second, the patient must be aged older than 3 months but younger than 12 years. Very small infants usually present with overly large VSDs that are not suitable for occlusion. Conversely, when a patient is older, the VSD features severe tricuspid adherence and thickening, which makes aligning the occluder with the septum difficult and increases the residual shunt likelihood. Third, the VSD must be $2 \mathrm{~mm}$ or farther away from the aortic valve. ${ }^{3,5}$ General contraindications include a misaligned VSD, an atrioventricular VSD beneath the septal leaflet, a VSD complicated with aortic valve incompetence, and infective endocarditis. These conditions are not suitable for an occluder, and correction requires $\mathrm{CPB}^{5}$

During the surgery, residual shunt is the most common problem encountered; however, any shunt $<1.5 \mathrm{~mm}$ in size and $2.5 \mathrm{~m} / \mathrm{second}$ in velocity is acceptable. A sustained new aortic regurgitation may result from using an inappropriately sized occluder or from an aortic valve injury, requiring VSDR surgery. First-degree atrioventricular block is common, and most cases will eventually subside. If the occluder migrates, emergency VSDR is essential. Irritating tachycardia is far less common, but if it occurs, the maneuver must be stopped. If the 
tachycardia is sustained or recurrent, a VSDR using CPB is required. Later-aggravated atrioventricular block and residual shunt can occur, although at a low rate $(1.7 \%$ in our study).

PDCVSD has been applied for the past decade, but further studies at multiple centers to examine the longterm outcomes are required.

\section{CONCLUSIONS}

When VSD is indicated, PDCVSD is a safe modality with an acceptably mild early complication rate and a less severe late complication rate.

\section{References}

1. Hijazi ZM. Device closure of ventricular septal defects. Catheter Cardiovasc Interv. 2003;60:107-14.

2. Bacha EA, Cao QL, Galantowicz ME, Cheatham JP, Fleishman CE, Weinstein SW, et al. Multicenter experience with perventricular device closure of muscular ventricular septal defects. Pediatr Cardiol. 2005;26:169-75

3. Xing Q, Pan S, An Q, Zhang Z, Li J, Li F, et al. Minimally invasive perventricular device closure of perimembranous ventricular septal defect without cardiopulmonary bypass: multicenter experience and mid-term follow-up. J Thorac Cardiovasc Surg. 2010;139:1409-15.

4. Amin Z, Danford DA, Lof J, Duncan KF, Froemming S. Intraoperative device closure of perimembranous ventricular septal defects without cardiopulmonary bypass: preliminary results with the perventricular technique. J Thorac Cardiovasc Surg. 2004;127:234-41

5. Zhu D, Gan C, Li X, An Q, Luo S, Tang H, et al. Perventricular device closure of perimembranous ventricular septal defect in pediatric patients: technical and morphological considerations. Thorac Cardiovasc Surg. 2013;61:300-6.

\title{
Arterial switch operation for transposition of the great arteries with anomalies of cardiac situs and aortic position
}

\author{
Sachin Talwar, MCh, Aandrei Jivendra Jha, MS, Shiv Kumar Choudhary, MCh, \\ Palleti Rajashekar, MCh, and Balram Airan, MCh, New Delhi, India
}

\section{Supplemental material is available online.}

A prime determinant of successful outcome after the arterial switch operation (ASO) is an accurate transfer of coronary buttons to the neoaorta. ${ }^{1}$ Our experience with the ASO in patients with transposition of the great arteries and unusual relationship of the great arteries (levoposed aorta) and dextrocardia is presented here with details of appropriate modifications in surgical technique.

\section{MATERIALS AND METHODS}

Between January 2002 and January 2013, a series of 8 patients with transposition of the great arteries and either dextrocardia or aorta positioned anterior and to the left (levoposed aorta) underwent the ASO (Table 1). Of the 3 patients with dextrocardia, 1 patient had situs inversus totalis and the other 2 had normal visceral situs. Six patients, among them the patient with situs inversus totalis, had a levoposed aorta. Left-sided aortic arch was present in $50 \%$. Two patients had both coronaries arising from a single ostium from sinus 2. Five patients had the usual coronary anatomy for

From the Cardiothoracic Centre, All India Institute of Medical Sciences, New Delhi, India.

Disclosures: Authors have nothing to disclose with regard to commercial support.

Received for publication Feb 19, 2013; revisions received July 30, 2013; accepted for publication Aug 15, 2013; available ahead of print Oct 11, 2013.

Address for reprints: Sachin Talwar, MCh, Department of Cardiothoracic and Vascular Surgery, All India Institute of Medical Sciences, New Delhi 110029, India (E-mail: sachintalwar@hotmail.com).

J Thorac Cardiovasc Surg 2013;146:1553-6

$0022-5223 / \$ 36.00$

Copyright $\odot 2013$ by The American Association for Thoracic Surgery

http://dx.doi.org/10.1016/j.jtcvs.2013.08.052 transposition. Patient 7, who had situs inversus totalis with mirror-image dextrocardia, had a peculiar "double looping" coronary pattern with inverted origins of circumflex and right coronary arteries (a mirror image of the Yacoub type E coronary pattern). The Lecompte maneuver was carried out in 3 patients, including patient 7 . Juxtaposed right and left atrial appendages were present in 2 patients and 1 patient, respectively.

All patients underwent aortobicaval cannulation, and standard hypothermic $\left(28^{\circ} \mathrm{C}\right)$ cardiopulmonary bypass was instituted. The aorta and pulmonary artery were dissected free, and branch pulmonary arteries were completely mobilized. The ductus arteriosus was isolated, transfixed, and divided. The aorta was crossclamped, cold blood cardioplegia was delivered into the aortic root, and the heart was arrested. Transatrial ventricular septal defect closure was performed wherever needed, except in patients 5 and 7 , in whom closure was performed through the proximal neoaorta. The aorta was transected well above the sinotubular junction. Coronary buttons were harvested, and the main pulmonary artery (MPA) was divided at the confluence.

In all 5 cases of levocardia with levoposed aorta, the proximal right ventricular outflow tract (RVOT) was reconstructed first by suturing autologous pericardium to the margins of the defect created in the proximal aorta (neopulmonary artery) after harvesting of the coronary buttons. After RVOT reconstruction, a longitudinal wedge of tissue was excised from the proximal MPA (neoaorta), well above the sinuses, and the coronary button was sutured in place. Because of the peculiar situation in which the aorta was left-sided, the decision to perform the Lecompte maneuver was always postponed towards the end. Also it was anticipated that, the RVOT might impinge on the transferred coronary artery. To prevent this, the arteriotomy in the distal MPA was extended leftward. Starting from the center of the arteriotomy and up to its rightward end, the distal MPA was closed. The proximal MPA was then anastomosed to the under surface of the left pulmonary artery to shift the RVOT in a leftward direction, thus moving it away from the coronary button. If the Lecompte maneuver was not carried out, both the great arteries would come to lie parallel to each other (Figures 1 and 2).

In patients with dextroposed aorta where the aorta was situated to the right and anterior (patients 1 and 5), coronary buttons were transferred routinely and the Lecompte maneuver was performed. 